American Journal of Physical Chemistry
2019; 8(3): 58-65
http://www.sciencepublishinggroup.com/j/ajpc
doi: $10.11648 /$ j.ajpc.20190803.12
ISSN: $2327-2430$ (Print); ISSN: $2327-2449$ (Online)

\title{
On the Problem of Gypsum Deposition in the Dead Sea in the Case of Two Seas Canal Construction
}

\author{
Krumgalz Boris ${ }^{1,2}$ \\ ${ }^{1}$ Environmental Studies and Modeling, Nesher, Israel \\ ${ }^{2}$ National Institute of Oceanography, Tel Shikmona, Haifa, Israel
}

Email address:

krumgalz@gmail.com

To cite this article:

Krumgalz Boris. On the Problem of Gypsum Deposition in the Dead Sea in the Case of Two Seas Canal Construction. American Journal of Physical Chemistry. Vol. 8, No. 3, 2019, pp. 58-65. doi: 10.11648/j.ajpc.20190803.12

Received: October 9, 2019; Accepted: October 29, 2019; Published: November 8, 2019

\begin{abstract}
The Dead Sea is a terminal lake, being the lowest and one of the most saline lakes on earth. For more than last fifty years the water level of the Dead Sea drastically decreased resulting in a drop of more than $30 \mathrm{~m}$ since beginning of sixties of the last century. The present level and size of the Dead Sea and its development are determined by a negative water balance between precipitation, runoff and evaporation. One of the possible ways to stop reducing the surface level of the Dead See and even to reverse this process, it is to supply seawater by connecting the Dead Sea with a world ocean system. The first and the most suitable choice discussed from the seventies of the last century was a canal connecting the Dead Sea with the Mediterranean Sea. However, due to geopolitical situation in this region the project of Dead Sea - Mediterranean Sea canal was abandoned, and another two seas canal variant has been studying for the last several decades, namely a canal between the Dead Sea and the Rea Sea via the Gulf of Eilat/Aqaba. The problems attracting the wide public attention for this canal construction are the ecological effects of mixing the waters of the Dead Sea and seawater from the Red Sea if the canal between these two seas will be built. There are some fears that under certain conditions, a layer of gypsum crystals floating on the Dead Sea surface will be formed causing some undesirable ecological effects in local environment. In the present article the rates of the deposition of gypsum crystals in the mixtures of the Dead Sea water with seawater were estimated by using the experimental viscosity and density values of these waters mixtures. The results of these calculations allowed us to assume that there is no danger that gypsum crystals, which can be formed under certain conditions during mixing of Dead Sea and seawater, will float on the Dead Sea water surface forever and after a relatively short period of time, depending on the dimensions of the crystals, gypsum crystals will sink to the bottom.
\end{abstract}

Keywords: Dead Sea, Mediterranean Sea, Two Seas Canal, Seawater, Viscosity, Density, Gypsum Crystals, Crystal Deposition

\section{Introduction}

The Dead Sea is a large and deep terminal lake (i.e. a lake with no outlet) situated in the lowest section of the Jordan Rift Valley between Israel and Jordan, being the lowest terrestrial site and one of the most saline lakes on earth. The present level and size of the Dead Sea and its development are determined by a negative water balance between precipitation, runoff and evaporation [1-3]. Compared with evaporated ordinary seawater of the same chlorinity, the Dead Sea water is deficient in sodium, potassium, magnesium, and sulfate while enriched with calcium and bromide. The present-day Dead Sea is either close to saturation or oversaturated with respect to several mineral phases as halite, gypsum, barite and celestite. Until 1977, the Dead Sea was consisted of two parts, a large and deep northern basin and a smaller and very shallow southern one, connected via the Lynch straits [4]. These both basins have suffered considerable changes in recent years through both climatic causes and man-made ones that include the potash industry set up in the 1930's and the increasing exploitation of the Jordan river waters for irrigation. For more than last fifty years the water level of the Dead Sea drastically decreased resulting in a drop of more than $30 \mathrm{~m}$ since beginning of sixties of the last century. Negative water budget has reduced the surface level of the Dead Sea below 
the sill depth of the Lynch straits and since the beginning of 1977, the southern basin separated from the main Dead Sea body became a pond maintained by a dike and filled with waters pumped in from the northern basin [5]. Since then the southern basin of the Dead Sea is used by the Dead Sea Works operating on the Israeli side and APC (Arabian Potash Company) on the Jordanian side as evaporation pond for the potash and magnesium compounds production via carnallite $\left(\mathrm{KMgCl}_{3} \cdot 6 \mathrm{H}_{2} \mathrm{O}\right)$ precipitation. In the present paper the "Dead Sea" refers solely to what used to be the northern basin.

One of the possible ways to stop reducing the surface level of the Dead See and even to reverse this process, it is to supply seawater by connecting the Dead Sea with a world ocean system. The first and the most suitable choice discussed was a canal connecting the Dead Sea with Mediterranean Sea. Due to the importance of the Dead Sea for Israel's economy and in order to understand the possible effects of the proposed canal on the natural processes in the Dead Sea water body, various physico-chemical properties of the Dead Sea water before and after mixing with entering Mediterranean seawater have been studied during seventies and eighties of the last century. These investigations included studies of the changes in chemical composition of the Dead Sea and precipitation processes in it [6-12], the physical structure of the Dead Sea water body [5, 13-15], and some thermodynamic aspects of Dead Sea brines [8, 10, 16-18]. However, due to geopolitical situation in this region the project Dead Sea - Mediterranean Sea canal was abandoned and another two seas canal variant has been studying for the last twenty years, namely a canal between the Dead Sea and the Rea Sea via the Gulf of Eilat/Aqaba [19]. We should emphasize that the experimental part of the present study was conducted in eighties of the last century when the general intention was to build a two seas canal between the Dead Sea and the Mediterranean Sea. However, since the chemical compositions of the Mediterranean and Red Sea waters are relatively very similar with small difference in total salinity, the results obtained for mixtures of Dead Sea water with Mediterranean water can be used for the discussion of the phenomena of gypsum precipitation in the mixtures of Dead Sea water with Red Sea water.

The problems attracting the wide scientific attention are the ecological effects of mixing the waters of the Dead Sea and seawater if the canal between these two seas will be built. There are some fears that under certain conditions, a layer of gypsum $\left(\mathrm{CaSO}_{4} \cdot 2 \mathrm{H}_{2} \mathrm{O}\right)$ crystals floating on the Dead Sea surface will be formed causing some undesirable ecological effects in local environment. The deposition of the formed crystal will take some time. The minerals deposition in water column is determined by three stages which are: a) the nucleation of a new crystal phase; b) the crystal growth; c) crystal precipitation. If the formed gypsum crystals will not settle quickly to the bottom it may influence the general appearance of the Dead Sea water. This gypsum layer would lead to a change in color of Dead Sea water and also could harm potash production at the Dead Sea Works operating on the Israeli side and APC (Arabian Potash Company) on the
Jordanian side.

Even Dead Sea waters are oversaturated with respect to some calcium, barium and strontium salts $[17,18,20,21]$ no massive deposition of these minerals was observed under present sea conditions [22]. The spontaneous precipitation of some of these minerals in Dead Sea water has been observed only in very rare cases. A whiting (whitening) phenomenon observed in the Dead Sea from August to December 1943 was described in [23-25]. Bloch et al. [23] estimated that about $80 \%$ of the white solid were calcium carbonate. However, the authors did not find any mention of such an outstanding event in the previous history of the Dead Sea except a quotation from the famous Greek physician Galen, who visited the Dead Sea at about 158 C.E. and stated that the waters of the Dead Sea "appear at first glance whiter and heavier than all Seas". Later, Neev [26] again observed a whiting in the Dead Sea in August 1959. He suggested that aragonite was precipitated during whiting when the Dead Sea water temperatures reach their annual maximum. Friedman $[27,28]$ concluded that the mechanism of whiting in the Dead Sea was physico-chemical precipitation of aragonite in contrast to the biologically induced mechanism for Bahaman whiting [29]. The mechanism of whiting in the Dead Sea has not yet been explained completely, although it is obvious that kinetic factors are also responsible.

The problem of gypsum formation and sedimentation in the Dead Sea has been considered by several research groups. Neev and Emery [4] have shown that one of the components in the Dead Sea bottom sediments was gypsum, which has been precipitated from Dead Sea waters. These authors also observed that suspended material in water samples consisted chiefly of gypsum and aragonite. However, Levy [30] did not find significant amounts of gypsum in suspended matter samples taken from different depths of the Dead Sea and in samples collected in sediment traps [31]. In the beginning of eighties last century, Katz et al. [9] and Krumgalz and Millero $[10,11]$ have demonstrated that Dead Sea waters are oversaturated with respect to gypsum. The oversaturation of the Dead Sea with respect to gypsum and the virtual absence of gypsum crystals in suspended matter mean that the gypsum crystallization process in the Dead Sea under present conditions was limited by some kinetic factors. Recently Reznik et al. [32-35] have studied kinetics of gypsum nucleation and crystal growth from Dead Sea brine and from Dead Sea and Red Sea seawater mixtures.

If the above discussed two seas canal will be built, the mixing of the two different water bodies will take place. The problem of gypsum solubility in the mixtures of Dead Sea and Mediterranean Sea waters at different ratios and in their concentrates obtained by evaporation has been examined experimentally by Katz et al. [9] and theoretically by Krumgalz and Millero [11]. Dead Sea waters are known to be much richer in $\mathrm{Ca}^{2+}$ cations and much poorer in $\mathrm{SO}_{4}^{2-}$ anions than world ocean waters. Therefore, when the mixing of such different water bodies will take place, two opposite effects will occur: the $\mathrm{SO}_{4}^{2-}$ anion concentration will increase, but the $\mathrm{Ca}^{2+}$ cation concentration will decrease 
in the mixtures of these waters. Krumgalz and Millero [11] have shown that the mixtures enriched with Dead Sea waters are over-saturated with respect to gypsum. When Dead Sea waters are mixed with Mediterranean Sea water, the degree of gypsum saturation $\left(\Omega_{\text {gypsum }}\right)$ goes through a maximum of ca. 1.77 at the weight portion of Dead Sea water equal to 0.909. The dependence of the degree of gypsum saturation from ionic strength of Dead Sea water and Mediterranean seawater mixtures at $25^{\circ} \mathrm{C}$ was described by the following equation [11]:

$$
\Omega_{\text {gypsum }}=\exp \left(-3.3986+3.3242 \cdot I_{m}^{0.5}-1.0646 \cdot \mathrm{I}_{\mathrm{m}}+0.131074 \cdot I_{m}^{1.5}\right)
$$

where $I_{m}$ is the ionic strength of Dead Sea - Mediterranean Sea waters mixtures in molality units. After reaching the weight fraction of Dead Sea water in the mixtures with Mediterranean Sea water the value of ca. 0.444, the considered mixtures become under-saturated with respect to gypsum $\left(\Omega_{\text {gypsum }}<1\right)$. The results of gypsum saturation in the mixtures of Dead Sea water with Red sea water obtained by Reznik et al. [33, 35] are comparative with the results of Krumgalz and Millero [11] for the mixtures of Dead Sea water with Mediterranean Sea water.

Reznik et al. [33] suggested that gypsum precipitation in the Dead Sea system is very slow and is limited by nucleation rate. The question is how long will it take for the gypsum crystals to sink to the sea bottom? In this study, we estimated the rate of deposition of gypsum crystals in the Dead Sea water and its mixtures with the Mediterranean Sea water based on experimentally determined viscosity and density of such mixtures.

\section{Experimental Part}

Nine different mixtures of Dead Sea and Mediterranean
Sea waters prepared by weight are summarized in Table 1. According to the calculations [11], only five first solutions are over-saturated with respect to gypsum. Ionic compositions (only for major ions) of the mixtures were calculated from the experimentally determined Dead Sea and Mediterranean Sea water concentrations. Sodium and potassium ions concentrations were determined using a Flame Photometer IL443 with a precision better than $\pm 0.2 \%$. Calcium ion concentrations were found by complexometric titration with EGTA with an accuracy of $\pm 0.2 \%$ [36] using a Ca-selective electrode Radiometer F2110Ca. The total content of calcium and magnesium ions was determined by complexometric titration with EDTA at $\mathrm{pH}=9.5$ using a calcium selective electrode. The magnesium content was then calculated as the difference between the total magnesium and calcium content and calcium concentration found by separate titrations. The sulfate concentration was determined by the conventional gravimetric method with $\mathrm{BaCl}_{2}$. The total content of chloride and bromide anions was found by argentometric titration with a silver electrode. Bromide determination was carried out by the iodometric method described in [37].

Table 1. Composition of Dead Sea water (DSW), Mediterranean Sea water (MSW) and their different mixtures.

\begin{tabular}{|c|c|c|c|c|c|c|c|c|c|c|}
\hline \multirow{2}{*}{ Mixture } & \multicolumn{2}{|c|}{ Weight portion, \% } & \multicolumn{8}{|c|}{ Ionic concentrations in molality units } \\
\hline & DSW & MSW & $\mathrm{Na}^{+}$ & $\mathbf{K}^{+}$ & $\mathrm{Ca}^{2+}$ & $\mathrm{Mg}^{2+}$ & $\mathrm{Cl}^{-}$ & $\mathrm{Br}^{-}$ & $\mathrm{SO}_{4}{ }^{2-}$ & $\mathbf{I}_{\mathrm{m}}$ \\
\hline DSW & 100 & 0 & 1.834 & 0.2125 & 0.4584 & 1.943 & 6.749 & 0.07202 & 0.005576 & 9.248 \\
\hline$\# 1$ & 90 & 10 & 1.672 & 0.1871 & 0.4018 & 1.704 & 5.974 & 0.06300 & 0.00914 & 8.179 \\
\hline$\# 2$ & 80 & 20 & 1.519 & 0.1631 & 0.3484 & 1.479 & 5.244 & 0.05451 & 0.01250 & 7.171 \\
\hline$\# 3$ & 70 & 30 & 1.375 & 0.1405 & 0.2981 & 1.267 & 4.556 & 0.04650 & 0.01566 & 6.221 \\
\hline$\# 4$ & 60 & 40 & 1.239 & 0.1192 & 0.2505 & 1.067 & 3.904 & 0.03893 & 0.01866 & 5.322 \\
\hline$\# 5$ & 50 & 50 & 1.110 & 0.09894 & 0.2055 & 0.8767 & 3.288 & 0.03176 & 0.02149 & 4.471 \\
\hline \#7 & 30 & 70 & 0.8714 & 0.06157 & 0.1222 & 0.5256 & 2.149 & 0.01851 & 0.02673 & 2.899 \\
\hline$\# 8$ & 20 & 80 & 0.7610 & 0.04427 & 0.08370 & 0.3631 & 1.622 & 0.01237 & 0.02916 & 2.172 \\
\hline$\# 9$ & 10 & 90 & 0.6560 & 0.02780 & 0.04702 & 0.2085 & 1.120 & 0.006533 & 0.03146 & 1.479 \\
\hline MSW & 0 & 100 & 0.5559 & 0.01211 & 0.01206 & 0.06107 & 0.6414 & 0.000968 & 0.03366 & 0.8188 \\
\hline
\end{tabular}

\section{Results}

The results of the viscosity ( $v$ and $\eta$ are kinematic and dynamic viscosity, respectively) and density ( $\rho)$ measurements of Dead Sea water, Mediterranean Sea water and their mixtures at various temperatures are presented in
Table 2. Density measurements have been carried out with a flow digital densimeter, Sodev vibrating tube densimeter, described in [38]. Viscosity measurements with a precision of $\pm 0.1 \%$ have been conducted with Ubbelohde capillary viscometers on the automated viscosity measuring instrument "Lauda Viscoboy".

Table 2. Kinematic ( $v$ ) and dynamic ( $\eta$ ) viscosities and density of Dead Sea water, Mediterranean Sea water and their mixtures at various temperatures.

\begin{tabular}{|c|c|c|c|c|c|c|c|c|c|c|c|c|c|}
\hline \multirow{2}{*}{ Solution } & \multirow{2}{*}{$\mathbf{I}_{\mathbf{m}}$} & \multicolumn{3}{|l|}{$15^{\circ} \mathrm{C}$} & \multicolumn{3}{|l|}{$25^{\circ} \mathrm{C}$} & \multicolumn{3}{|l|}{$35^{\circ} \mathrm{C}$} & \multicolumn{3}{|l|}{$45^{\circ} \mathrm{C}$} \\
\hline & & $\mathrm{v}, \mathrm{cSt}$ & $\rho_{\mathrm{av}}, \mathbf{g} \cdot \mathrm{cm}^{-3}$ & $\eta, \mathbf{c P}$ & $\mathrm{v}, \mathrm{cSt}$ & $\rho_{\mathrm{av}}, \mathbf{g} \cdot \mathrm{cm}^{-3}$ & $\eta, \mathbf{c P}$ & $v, \mathrm{cSt}$ & $\rho_{\mathrm{av}}, \mathbf{g} \cdot \mathrm{cm}^{-3}$ & $\eta, \mathbf{c P}$ & $\mathrm{v}, \mathrm{cSt}$ & $\rho_{\mathrm{av}}, \mathbf{g} \cdot \mathrm{cm}^{-3}$ & $\eta, \mathrm{cP}$ \\
\hline DSW & 9.248 & 2.873 & 1.230616 & 3.536 & 2.234 & 1.226194 & 2.740 & 1.792 & 1.222161 & 2.190 & 1.471 & 1.217426 & 1.791 \\
\hline \#1 & 8.179 & 2.520 & 1.208941 & 3.047 & 1.971 & 1.204197 & 2.373 & 1.584 & 1.199086 & 1.899 & 1.310 & 1.194447 & 1.564 \\
\hline \#2 & 7.171 & 2.236 & 1.189036 & 2.658 & 1.760 & 1.182871 & 2.082 & 1.422 & 1.178603 & 1.676 & 1.180 & 1.176255 & 1.388 \\
\hline \#3 & 6.221 & 1.998 & 1.165889 & 2.329 & 1.587 & 1.161906 & 1.844 & 1.285 & 1.157708 & 1.487 & 1.070 & 1.153305 & 1.234 \\
\hline
\end{tabular}




\begin{tabular}{|c|c|c|c|c|c|c|c|c|c|c|c|c|c|}
\hline \multirow{2}{*}{ Solution } & \multirow{2}{*}{$\mathbf{I}_{\mathbf{m}}$} & \multicolumn{3}{|l|}{$15^{\circ} \mathrm{C}$} & \multicolumn{3}{|l|}{$25^{\circ} \mathrm{C}$} & \multicolumn{3}{|l|}{$35^{\circ} \mathrm{C}$} & \multicolumn{3}{|l|}{$45^{\circ} \mathrm{C}$} \\
\hline & & $\mathrm{v}, \mathrm{cSt}$ & $\rho_{\mathrm{av}}, \mathbf{g} \cdot \mathrm{cm}^{-3}$ & $\eta, \mathbf{c P}$ & $\mathrm{v}, \mathrm{cSt}$ & $\rho_{\mathrm{av}}, \mathbf{g} \cdot \mathrm{cm}^{-3}$ & $\eta, \mathbf{c P}$ & $\mathrm{v}, \mathrm{cSt}$ & $\rho_{\mathrm{av}}, \mathbf{g} \cdot \mathrm{cm}^{-3}$ & $\eta, \mathbf{c P}$ & $v, \mathrm{cSt}$ & $\rho_{\mathrm{av}}, \mathbf{g} \cdot \mathrm{cm}^{-3}$ & $\eta, \mathbf{c P}$ \\
\hline$\# 4$ & 5.322 & 1.820 & 1.145129 & 2.084 & 1.440 & 1.141312 & 1.643 & 1.170 & 1.137206 & 1.331 & 0.979 & 1.132818 & 1.109 \\
\hline$\# 5$ & 4.472 & 1.659 & 1.124956 & 1.866 & 1.323 & 1.121277 & 1.483 & 1.077 & 1.117278 & 1.204 & 0.902 & 1.112922 & 1.004 \\
\hline \#6 & 3.665 & 1.540 & 1.105257 & 1.702 & 1.222 & 1.101607 & 1.346 & 0.996 & 1.097680 & 1.093 & 0.834 & 1.093488 & 0.912 \\
\hline$\# 7$ & 2.900 & 1.434 & 1.085780 & 1.557 & 1.141 & 1.082371 & 1.235 & 0.929 & 1.078574 & 1.001 & 0.777 & 1.074376 & 0.835 \\
\hline$\# 8$ & 2.172 & 1.337 & 1.066833 & 1.426 & 1.067 & 1.063427 & 1.135 & 0.868 & 1.059721 & 0.920 & 0.727 & 1.057680 & 0.769 \\
\hline \#9 & 1.479 & 1.265 & 1.048002 & 1.326 & 1.003 & 1.044830 & 1.048 & 0.815 & 1.041256 & 0.849 & 0.682 & 1.037258 & 0.707 \\
\hline
\end{tabular}

\section{Discussion}

The deposition rate of small particles in liquid medium under the condition of dynamic equilibrium is determined by the Stokes law. According to the Stokes law, the resistance force of a medium to the deposition of small particles in this medium is expressed in the form:

$$
\mathrm{f}=3 \cdot \pi \cdot d \cdot \eta \cdot \omega_{d e p}
$$

where $\mathrm{f}$ is the resistance force, $\mathrm{d}$ is the diameter of a particle, $\eta$ is the dynamic viscosity of a medium and $\omega_{\text {dep }}$ is the deposition rate.

Under the condition of dynamic equilibrium of the deposition process, the resistance force will be equal to the difference between the particle weight and the buoyant expulsive force (buoyancy force):

$$
\frac{\pi \cdot d^{3}}{6} \cdot g \cdot\left(\rho_{s}-\rho\right)=3 \cdot \pi \cdot d \cdot \eta \cdot \omega_{d e p}
$$

where $\mathrm{g}$ is the gravity acceleration $\left(\mathrm{g}=980.7 \mathrm{~cm} \cdot \mathrm{sec}^{-2}\right) ; \rho_{\mathrm{S}}$ is the density of the solid particle and $\rho$ is the density of a medium. Finally, the deposition rate of small particles in liquid medium under the condition of dynamic equilibrium is expressed according to the Stokes law as

$$
\omega_{d e p}=\frac{d^{2} \cdot g \cdot\left(\rho_{s}-\rho\right)}{18 \cdot \eta}=\frac{d^{2} \cdot g \cdot\left(\rho_{s}-\rho\right)}{18 \cdot v \cdot \rho}
$$

where $v$ the kinematic viscosity of a liquid medium. One of the problems arising when using the above equation is the calculating of a diameter of the particle under consideration. For the non-spherical particles in Eqns. (2), (3) and (4), the equivalent diameter $\left(\mathrm{d}_{\text {eqv }}\right)$ should be used. The $\mathrm{d}_{\text {eqv }}$ value is equal to the diameter of a sphere having the same volume (v) as the non-spherical particle under study:

$$
d_{e q v}=\sqrt[3]{\frac{6}{\pi}} \cdot v
$$

The deposition rate of particles of non-spherical configuration $\left(\omega_{d e p}^{n}\right)$ is less than the deposition rate of spherical particles having the same volumes. The deposition rate of non-spherical particles is equal to the deposition rate of spherical particles multiplied by the correction coefficient $\psi$ called the configurational coefficient:

$$
\omega_{d e p}^{n}=\psi \cdot \omega_{d e p}
$$

The configurational coefficient is always less than 1 , and its rough values can be found in Kasatkin [39, p.104]: for rounded particles $\psi \approx 0.77$, for angular particles $\psi \approx 0.66$, for oblong particles $\psi \approx 0.58$ and for lamellar particles $\psi \approx 0.43$.

The important question is concerned to the configurations of crystals which are formed during gypsum precipitation. The process of gypsum nucleation and its crystals' growth in mixtures of Mediterranean and Dead Sea waters has been studied by Levy and Kushnir [40]. According to their findings, gypsum crystals formed in the studied mixtures were, as a rule, prismatic with a length-wide ratio of 10:1. The crystal lengths were in the range between 15 and $120 \mu$ during 24 hours after two seas water mixing, with dominant length near $60 \mu$. In some rare cases Levy and Kushnir [40] have also found crystals like discs. The calculations of the configurational coefficients for such gypsum crystals can be carried out by the formulas reported by Lerman [41, p. 428]. The configurational coefficients of needle-form particles settling in parallel to their length $\left(\psi_{(\mid \ell)}\right)$ and settling perpendicularly to their length $\left(\psi_{(\perp \ell)}\right)$ are respectively represented by formulas:

$$
\begin{aligned}
\psi_{(\mid \ell)} & =\frac{3}{2} \cdot \frac{1 n(2 \cdot p)-0.5}{p^{2 / 3}} \\
\psi_{(\perp \ell)} & =\frac{3}{4} \cdot \frac{\ln (2 \cdot p)+0.5}{p^{2 / 3}}
\end{aligned}
$$

with $p=l / b$ where $\ell$ and $\mathrm{b}$ are the length and width of a particle, respectively.

It should be emphasized that Eqn. (2) is correct only when the deposition regime is laminar, i.e. the Reynolds criterion ( $R e$ ) is in the range $1 \cdot 10^{-4}<\operatorname{Re}<0.1$ [41, p. 265]. Therefore, after the calculation of $\omega_{\text {dep }}^{\prime}$ from Eqn. (6), the deposition regime should be checked by the Reynolds criterion calculation:

$$
R e=\frac{\omega_{d e p}^{\prime} \cdot d_{e q v} \cdot \rho}{\eta}=\frac{\omega_{d e p}^{\prime} \cdot d_{e q v}}{v}
$$

If the values of the Reynolds criterion are in the range $1 \cdot 10^{-4}<\operatorname{Re}<0.1$, the $\omega_{\text {dep }}^{\prime}$ value calculated by Eqn. (6) gives the real value of the deposition rate. The estimation of the deposition rate of gypsum crystals in Dead Sea waters and 
their mixtures with Mediterranean Sea water was carried out by using density and viscosity of the mixtures under consideration and the dimensions of gypsum crystals formed in these mixtures according to [40].

Using our measurements of the density and viscosity of Dead Sea water and its mixtures with Mediterranean Sea water (Table 2), we calculated the deposition rate of gypsum crystals with equivalent diameters of $12,15,20$ and $25 \mu$ at different temperatures $\left(15,25\right.$ and $\left.35^{\circ} \mathrm{C}\right)$. When calculating $\omega_{d e p}^{\prime}$ we used the density of gypsum as $\rho_{\mathrm{s}}=2.32 \mathrm{~g} \mathrm{~cm}^{-3}$ [42] and the configurational coefficients $\Psi_{(\mid \ell)}=0.807$ and $\psi_{(\perp \ell)}$
$=0.565$ calculated by Eqn. $(7$ and 8$)$, using $p=10$, since the gypsum prismatic crystals can be considered as oblong or needle-form particles.

The values of the Reynolds criterion are also presented in Tables 3 and 4 and they show that, except for three cases marked with * in these Tables, the other values of Reynolds criteria are between $1 \cdot 10^{-4}$ and $64 \cdot 10^{-4}$ that means that the deposition regime is laminar. The analysis of the data presented in Tables 3 and 4 and Figures $1 \mathrm{a}$ and $1 \mathrm{~b}$ shows that there is a strong dependence of the deposition rate of gypsum crystals on temperature and on the weight fraction of Mediterranean Sea water in the mixtures with Dead Sea water.

Table 3. Rate of deposition (cm $\left.\cdot \sec ^{-1} \cdot 10^{3}\right)$ of gypsum crystals of various sizes (equivalent diameters in $\mu$ ) and Reynolds criterion in parenthesis (Re $\left.10^{4}\right)$ at different temperatures with $\psi_{(\perp \ell)}=0.565$.

\begin{tabular}{|c|c|c|c|c|c|c|c|c|c|c|c|c|c|}
\hline \multirow{2}{*}{ Solution } & \multirow{2}{*}{$\mathbf{I}_{\mathbf{m}}$} & \multicolumn{4}{|l|}{$15^{\circ} \mathrm{C}$} & \multicolumn{4}{|l|}{$25^{\circ} \mathrm{C}$} & \multicolumn{4}{|l|}{$35^{\circ} \mathrm{C}$} \\
\hline & & $12 \mu$ & $15 \mu$ & $20 \mu$ & $25 \mu$ & $12 \mu$ & $15 \mu$ & $20 \mu$ & $25 \mu$ & $12 \mu$ & $15 \mu$ & $20 \mu$ & $25 \mu$ \\
\hline \multirow[t]{2}{*}{ DSW } & 9.248 & - & 2.13 & 3.79 & 5.93 & 1.77 & 2.77 & 4.92 & 7.68 & 2.22 & 3.47 & 6.17 & 9.64 \\
\hline & & $(0.6)^{*}$ & $(1.1)$ & (2.6) & $(5.2)$ & $(1.0)$ & (1.9) & (4.4) & $(8.6)$ & $(1.5)$ & (2.9) & (6.9) & (13.5) \\
\hline \multirow[t]{2}{*}{$\# 1$} & 8.179 & - & 2.52 & 4.49 & 7.01 & 2.08 & 3.26 & 5.79 & 9.05 & 2.62 & 4.09 & 7.27 & 11.36 \\
\hline & & $(0.8)^{*}$ & $(1.5)$ & (3.6) & $(7.0)$ & $(1.3)$ & $(2.5)$ & (5.9) & (11.5) & $(2.0)$ & (3.9) & $(9.2)$ & (17.9) \\
\hline \multirow[t]{2}{*}{$\# 2$} & 7.171 & 1.89 & 2.95 & 5.24 & 8.19 & 2.42 & 3.78 & 6.73 & 10.51 & 3.02 & 4.72 & 8.38 & 13.10 \\
\hline & & $(1.0)$ & $(2.0)$ & $(4.7)$ & $(9.2)$ & $(1.7)$ & $(3.2)$ & (7.6) & (14.9) & $(2.6)$ & $(5.0)$ & (11.8) & $(23.0)$ \\
\hline$\# 3$ & & (1.3) & $(2.6)$ & $(6.1)$ & (11.9) & $(2.1)$ & (4.1) & $(9.8)$ & (19.0) & $(3.2)$ & (6.3) & (15.0) & (29.3) \\
\hline \multirow[t]{2}{*}{$\# 4$} & 5.322 & 2.50 & 3.90 & 6.94 & 10.85 & 3.18 & 4.97 & 8.83 & 13.80 & 3.95 & 6.17 & 10.96 & 17.12 \\
\hline & & (1.7) & $(3.2)$ & (7.6) & (14.9) & $(2.7)$ & $(5.2)$ & (12.3) & $(24.0)$ & $(4.1)$ & (7.9) & (18.8) & (36.6) \\
\hline \multirow[t]{2}{*}{$\# 5$} & 4.472 & 2.84 & 4.44 & 7.89 & 12.32 & 3.58 & 5.60 & 9.95 & 15.55 & 4.43 & 6.92 & 12.31 & 19.23 \\
\hline & & (2.1) & $(4.0)$ & $(9.5)$ & (18.6) & (3.3) & (6.4) & (15.0) & (29.4) & $(4.9)$ & (9.6) & (22.8) & (44.6) \\
\hline
\end{tabular}

* For these cases, the deposition regime is not laminar, since $\mathrm{Re}<1 \cdot 10^{-4}$, therefore, the calculated deposition rates are incorrect and not presented in the table.

Table 4. Rate of deposition (cm $\left.\mathrm{sec}^{-1} \cdot 10^{3}\right)$ of gypsum crystals of various sizes (equivalent diameters in $\mu$ ) and Reynolds criterion in parenthesis (Re.10 $0^{4}$ ) at different temperatures with $\psi_{(}(\ell)=0.807$.

\begin{tabular}{|c|c|c|c|c|c|c|c|c|c|c|c|c|c|}
\hline \multirow{2}{*}{ Solution } & \multirow{2}{*}{$\mathbf{I}_{\mathbf{m}}$} & \multicolumn{4}{|l|}{$15^{\circ} \mathrm{C}$} & \multicolumn{4}{|l|}{$25^{\circ} \mathrm{C}$} & \multicolumn{4}{|l|}{$35^{\circ} \mathrm{C}$} \\
\hline & & $12 \mu$ & $15 \mu$ & $20 \mu$ & $25 \mu$ & $12 \mu$ & $15 \mu$ & $20 \mu$ & $25 \mu$ & $12 \mu$ & $15 \mu$ & $20 \mu$ & $25 \mu$ \\
\hline DSW & 9.248 & $(0.8)^{*}$ & $\begin{array}{l}3.05 \\
(1.6)\end{array}$ & $\begin{array}{l}5.42 \\
(3.8)\end{array}$ & $\begin{array}{l}8.47 \\
(7.4)\end{array}$ & $\begin{array}{l}2.53 \\
(1.4)\end{array}$ & $\begin{array}{l}3.95 \\
(2.7)\end{array}$ & $\begin{array}{l}7.02 \\
(6.3)\end{array}$ & $\begin{array}{l}10.97 \\
(12.3)\end{array}$ & $\begin{array}{l}3.17 \\
(2.1)\end{array}$ & $\begin{array}{l}4.96 \\
(4.2)\end{array}$ & $\begin{array}{l}8.82 \\
(9.8)\end{array}$ & $\begin{array}{l}13.77 \\
(19.2)\end{array}$ \\
\hline$\# 1$ & 8.179 & $\begin{array}{l}2.31 \\
(1.1)\end{array}$ & $\begin{array}{l}3.61 \\
(2.2)\end{array}$ & $\begin{array}{l}6.41 \\
(5.1)\end{array}$ & $\begin{array}{l}10.01 \\
(9.9)\end{array}$ & $\begin{array}{l}2.98 \\
(1.8)\end{array}$ & $\begin{array}{l}4.65 \\
(3.5)\end{array}$ & $\begin{array}{l}8.27 \\
(8.4)\end{array}$ & $\begin{array}{l}12.92 \\
(16.4)\end{array}$ & $\begin{array}{l}3.74 \\
(2.8)\end{array}$ & $\begin{array}{l}5.84 \\
(5.5)\end{array}$ & $\begin{array}{l}10.38 \\
(13.1)\end{array}$ & $\begin{array}{l}16.22 \\
(25.6)\end{array}$ \\
\hline$\# 2$ & 7.171 & $\begin{array}{l}2.69 \\
(1.5)\end{array}$ & $\begin{array}{l}4.21 \\
(2.8)\end{array}$ & $\begin{array}{l}7.48 \\
(6.7)\end{array}$ & $\begin{array}{l}11.69 \\
(13.1)\end{array}$ & $\begin{array}{l}3.46 \\
(2.4)\end{array}$ & $\begin{array}{l}5.40 \\
(4.6)\end{array}$ & $\begin{array}{l}9.61 \\
(10.9)\end{array}$ & $\begin{array}{l}15.01 \\
(21.3)\end{array}$ & $\begin{array}{l}4.31 \\
(3.6)\end{array}$ & $\begin{array}{l}6.74 \\
(7.1)\end{array}$ & $\begin{array}{l}11.98 \\
(16.8)\end{array}$ & $\begin{array}{l}18.71 \\
(32.9)\end{array}$ \\
\hline \#4 & 5.322 & $\begin{array}{l}3.57 \\
(2.4)\end{array}$ & $\begin{array}{l}5.58 \\
(4.6)\end{array}$ & $\begin{array}{l}9.91 \\
(10.9)\end{array}$ & $\begin{array}{l}15.49 \\
(21.3)\end{array}$ & $\begin{array}{l}4.54 \\
(3.8)\end{array}$ & $\begin{array}{l}7.10 \\
(7.4)\end{array}$ & $\begin{array}{l}12.62 \\
(17.5)\end{array}$ & $\begin{array}{l}19.71 \\
(34.2)\end{array}$ & $\begin{array}{l}5.64 \\
(5.8)\end{array}$ & $\begin{array}{l}8.81 \\
(11.3)\end{array}$ & $\begin{array}{l}15.65 \\
(26.8)\end{array}$ & $\begin{array}{l}24.46 \\
(52.3)\end{array}$ \\
\hline$\# 5$ & 4.472 & $\begin{array}{l}4.05 \\
(2.9)\end{array}$ & $\begin{array}{l}6.34 \\
(5.7)\end{array}$ & $\begin{array}{l}11.26 \\
(13.6)\end{array}$ & $\begin{array}{l}17.60 \\
(26.5)\end{array}$ & $\begin{array}{l}5.12 \\
(4.6)\end{array}$ & $\begin{array}{l}8.00 \\
(9.1)\end{array}$ & $\begin{array}{l}14.21 \\
(21.5)\end{array}$ & $\begin{array}{l}22.21 \\
(42.0)\end{array}$ & $\begin{array}{l}6.33 \\
(7.1)\end{array}$ & $\begin{array}{l}9.89 \\
(13.8)\end{array}$ & $\begin{array}{l}17.58 \\
(32.6)\end{array}$ & $\begin{array}{l}27.46 \\
(63.7)\end{array}$ \\
\hline
\end{tabular}

* For this case, the deposition regime is not laminar, since $\mathrm{Re}<1 \cdot 10^{-4}$, therefore, the calculated deposition rate is incorrect and not presented in the table.

Both the increase of temperature and of the weight fraction of Mediterranean Sea water increases the deposition rate of gypsum crystals. For instance, for average gypsum crystals with sizes $6 \mu^{*} 3 \mu^{*} 60 \mu\left(\mathrm{d}_{\mathrm{eqv}}=12.73 \mu\right)$ found by Levy and Kushnir [40], the deposition rate at $25^{\circ} \mathrm{C}$ in Dead Sea water is equal to $7.17 \mathrm{~cm} \cdot \mathrm{h}^{-1}$, when particles are settled perpendicularly to their length, and $10.24 \mathrm{~cm} \cdot \mathrm{h}^{-1}$ when particles are settled in parallel to their length, but in the mixture with $\mathrm{I}_{\mathrm{m}}=4.4716$ (consisting of $50 \%$ Dead Sea water and $50 \%$ Mediterranean Sea water), the deposition rates are equal to 14.52 and $20.73 \mathrm{~cm} \mathrm{~h}^{-1}$, respectively. This means that the deposition of gypsum crystals with equivalent diameters more than $12 \mu$ in the water column of Dead Sea water and its mixtures with Mediterranean Sea water will be relatively very fast. Therefore, it seems to us that there is no danger that the gypsum crystals which can be formed under certain conditions will float on the water surface. After a relatively short period of time, depending on the dimensions of the crystals, gypsum crystals will sink to the bottom of the Dead Sea. In addition, in order to decrease the environmental effects of gypsum crystals formation due to the mixing the Dead Sea water with Red Sea water, it is worth to discharge Red Sea water several meters below the surface of the Dead Sea. 


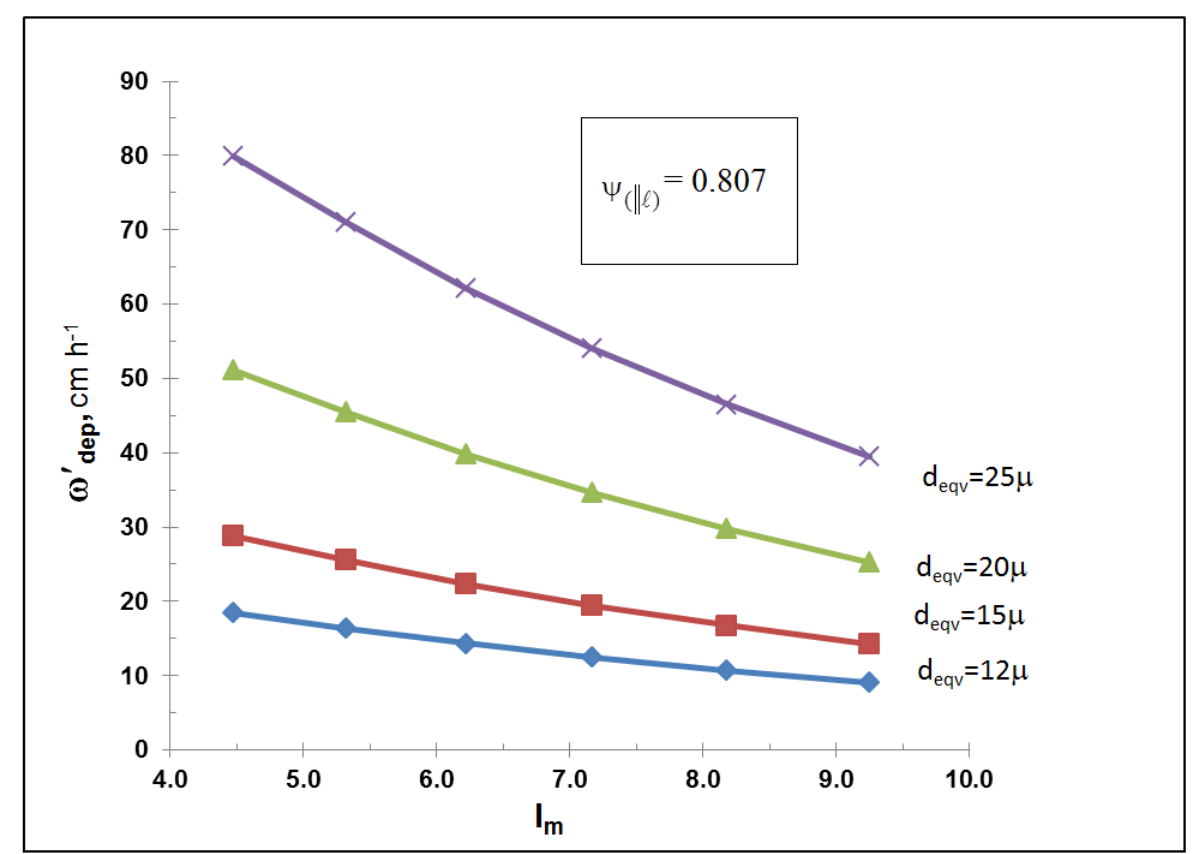

Figure 1. Deposition rate of gypsum crystals of various equivalent diameters in Dead Sea water and its mixtures with Mediterranean Sea water at $25^{\circ} \mathrm{C}$. $\psi_{((\ell)}=0.807$

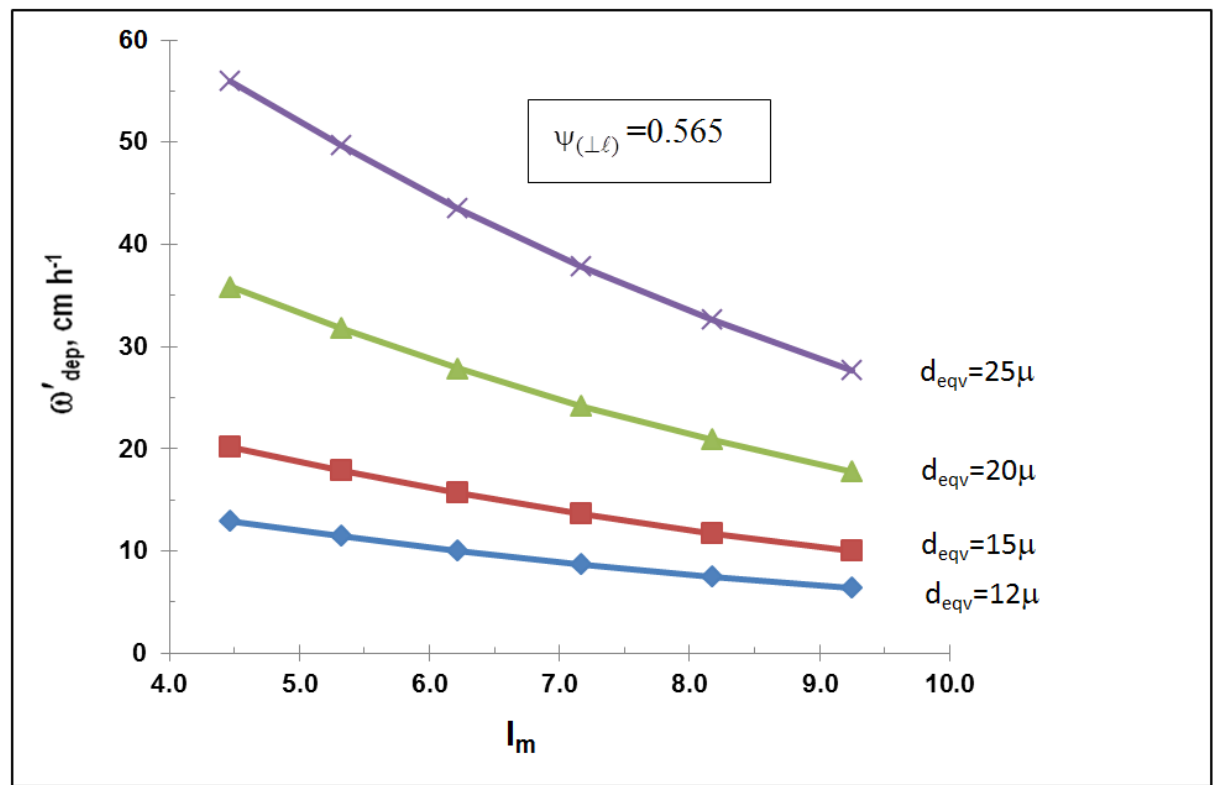

Figure 2. Deposition rate of gypsum crystals of various equivalent diameters in Dead Sea water and its mixtures with Mediterranean Sea water at $25^{\circ} \mathrm{C}$. $\psi_{(\perp \ell)}=0.565$.

\section{Conclusions}

For more than last fifty years the water level of the Dead Sea (a terminal lake, being the lowest and one of the most saline lakes on earth) drastically decreased resulting in a drop of more than $30 \mathrm{~m}$ since beginning of sixties of the last century. One of the possible ways to stop reducing the surface level of the Dead See and even to reverse this process, it is to supply seawater by connecting the Dead Sea with a world ocean system. Due to geopolitical situation in this region the project of Dead Sea - Mediterranean Sea canal, widely discussed in last century, was abandoned, and another two seas canal variant has been studying for the last several decades, namely a canal between the Dead Sea and the Rea Sea via the Gulf of Eilat/Aqaba. Some geochemical processes due to the mixing of the waters of the Dead Sea and of the Red Sea, if the canal between these two seas will be constructed, have been studied in the present article. There are some fears that under certain conditions, a layer of gypsum crystals floating on the Dead Sea surface will be 
formed causing some undesirable ecological effects in local environment and damaging the technological processes of the Dead Sea Works operating on the Israeli side and APC (Arabian Potash Company) on the Jordanian side. In the present article the rates of the deposition of gypsum crystals in the mixtures of the Dead Sea water with seawater were estimated by using the experimental viscosity and density values of these waters mixtures at various temperatures. The results of these calculations allowed us to assume that there is no danger that gypsum crystals, which can be formed under certain conditions during mixing of Dead Sea and seawater, will float on the Dead Sea water surface forever. After a relatively short period of time, depending on the dimensions of the crystals, gypsum crystals will sink to the bottom.

\section{Acknowledgements}

The author appreciates technical help of Ms. E. Braunstein and Ms. L. Aharoni in the experimental stages of this study. The work was supported by the Israeli Ministry of Energy.

\section{References}

[1] Neumann J., 1958. Tentative energy and water balances for the Dead Sea. Bull. Res. Counc. Israel, 7G, 137-163.

[2] Salhotra A. M., Harleman, D. R. F., 1984. A review of evaporation and stratification study of the Dead Sea. Sumaries of Investigations of the Mediterranean Dead Sea Canal, 5, 105131.

[3] Steinhorn I., 1997. Evaporation estimate for the Dead Sea: Essential considerations for saline lakes. In: Tina, M. Niemi, Ben-Avraham, Zvi and Gat, Joel (Editors), The Dead Sea. The Lake and Its Settings. Oxford Monographs on Geology and Geophysics. No. 36, Oxford University Press, pp 122-132.

[4] Neev, D. and Emery K. O. 1967. The Dead Sea. Depositional processes and environments of evaporites. Bull. Geol. Surv. Israel, 41, 147 pp., Geol. Surv., Ministry of Development, Jerusalem.

[5] Steinhorn, I. and G. Assaf. 1980. The physical structure of the Dead Sea water column, 1975-1977. In: A. Nissenbaum (Editor), Hypersaline Brines and Evaporitic Environments. Elsevier, Amsterdam, pp. 145-152.

[6] Nissenbaum, A. 1970. Chemical analysis of Dead Sea and Jordan River water, 1781-1830. Israel J. Chem., 8, 281-287.

[7] Nissenbaum, A. 1977. Minor and trace elements in Dead Sea water. Chem. Geol. 19, 99-111.

[8] Marcus, Y. 1977. Activities of potassium chloride and of water in Dead Sea brine. Geochim. Cosmochim. Acta, 41, 1739-1744.

[9] Katz, A., A. Starinsky, M. Taitel-Goldman and M. Beyth. 1981. Solubilities of gypsum and halite in the Dead Sea and in its mixtures with sea water. Limnol. Oceanogr., 26, 709-716.

[10] Krumgalz, B. S. and F. J. Millero. 1982. Physicochemical study of the Dead Sea waters. I. Activity coefficients of major ions in Dead Sea water. Mar. Chem., 11, 209-222.

[11] Krumgalz, B. S. and F. J. Millero. 1983. Physicochemical study of the Dead Sea waters. III. On gypsum saturation in Dead Sea waters and their mixtures with Mediterranean Sea water. Mar. Chem., 13, 127-137.

[12] Krumgalz, B. S. and Millero F. J., 1989. Halite solubility in Dead Sea waters. Mar. Chem., 27, 219-233.

[13] Assaf, G. and A. Nissenbaum. 1977. The evolution of the upper mass of the Dead Sea, 1819-1976. In: G. D. Green (Editor), Desertic Terminal Lakes, Utah State Univ., Logan, pp. 61-72.

[14] Steinhorn, I., G. Assaf, J. R. Gat, A. Nishry, A. Nissenbaum, M. Stiller, N. Beyth, D. Neev, R. Garber, G. M. Friedman and W. Weiss. 1979. The Dead Sea: deepening of the mixolimnion signifies the overturn of the water column. Science, 206, 55-57.

[15] Steinhorn, I., B.-Z. Gershorgen and G. Assaf. 1979. Mixing of flood waters within the Dead Sea and its salt evaporation pond. Israel J. Earth-Sci., 28, 77-85.

[16] Sass, E. and S. Ben-Yaakov. 1977. The carbonate system in hypersaline solutions: Dead Sea brines. Mar. Chem., 5, 183199.

[17] Krumgalz, B. S. 1996. Some aspects of physical chemistry of natural hypersaline waters. Recent Res. Develop. in Solution Chem. 1, 9-28.

[18] Krumgalz, B. S. 1997. Ion interaction approach to geochemical aspects of the Dead Sea. In, The Dead Sea. The Lake and Its Setting. (eds. Tina M. Niemi, Zvi Ben-Avraham, Joel R. Gat). New York - Oxford, Oxford University Press, pp 145-160.

[19] Gavrieli I., A. Bein, A. Oren. 2005. The expected impact of the 'Peace Conduit' project (the Red Sea-Dead Sea pipeline) on the Dead Sea. Mitig. Adapt. Strategies Glob. Change, 10, 3.

[20] Krumgalz B. S., A. Starinsky and K. Pitzer. 1999. Ion interaction approach: pressure effect on the solubility of some minerals in submarine brines and seawater. J. Solut. Chem., 28, 667-692.

[21] Krumgalz B. S., A. Hecht, A. Starinsky and A. Katz. 2000. Thermodynamic constraints on Dead Sea evaporation: how much can the Dead Sea evaporate? Chem. Geology, 165, 1-11.

[22] Levy, Y. 1988. Recent depositional environments in the Dead Sea. Geol. Surv. Israel, Jerusalem, Mar. Geol. Map. Div., Rep. $\mathrm{GSI} / 42 / 88,21 \mathrm{p}$.

[23] Bloch R., Littman H. Z. and Elazari-Volcani B. 1944. Occasional whiteness of the Dead Sea. Nature, 154, 402-403.

[24] Shalem N. 1949. Whitings of the waters of the Dead Sea. Nature, 164, 72.

[25] Rasumny J. 1962. The solubility of Neocomian formations from Sdome region (Israel) in various aqueous solutions. Congres National de Soc. des Savantes, Comp. Rend., 86, 387-388.

[26] Neev, D. 1963. Recent precipitation of calcium salts in the Dead Sea. Israel Res. Counc. Bull., 11G, 153-154.

[27] Friedman G. M. 1965. On the origin of aragonite in the Dead Sea, Israel J. Earth Sci., 14, 79-85.

[28] Friedman G. M. 1993. Biochemical and ultrastructural evidence for the origin of whitings: A biologically induced calcium carbonate precipitation mechanism, Comment. Geology, 21, 287-288. 
[29] Robbins L. L. and Blackwelder P. L. 1992. Biochemical and ultrastructural evidence for the origin of whitings: A biologically induced calcium carbonate precipitation mechanism. Geology, 20, 464-468.

[30] Levy, Y. 1981a. Quality and quantity of sediments collected in sediment trips in the Dead Sea 1980/81. Interim Report to the Ministry of Energy and Infrastructure.

[31] Levy, Y. 1981b. Suspended matter in the Dead Sea 1979/80. Report of Geological Survey of Israel, Marine Geology Division, $\mathrm{MG} / 1 / 81$.

[32] Reznik, I. J., I. Gavrieli and J. Ganor. 2009. Kinetics of gypsum nucleation and crystal growth from Dead Sea brine. Geochimica et Cosmochimica Acta, 73, 6218-6230.

[33] Reznik, I. J., J. Ganor I., Gal, A. and Gavrieli. 2009. Gypsum saturation degrees and precipitation potentials from Dead Seaseawater mixtures. Environ. Chem., 6, 416-423.

[34] Reznik, I. J., I. Gavrieli, Antler, G. and J. Ganor. 2011. Kinetics of gypsum crystal growth from high ionic strength solutions: A case study of Dead Sea - seawater mixtures. Geochimica et Cosmochimica Acta, 75, 2187-2199.

[35] Reznik, I. J., J. Ganor I., Gruber, C. and Gavrieli. 2012. Towards the establishment of a general rate law for gypsum nucleation. Geochimica et Cosmochimica Acta, 76, 75-87.
[36] Krumgalz, B. S. and R. Holzer. 1980. On the determination of calcium ion concentration in sea water. Limnol. Oceanogr., 25, 367-370.

[37] Morris, A. W. and J. P. Riley. 1966. The bromide/chlorinity and sulphate/chlorinity ratio in sea water. Deep-Sea Res., 13, 699705 .

[38] Picker, P., E. Tremblay and C. Jolicoeur. 1974. A highprecision digital readout flow densimeter for liquids. J. Solut. Chem., 3, 377-384.

[39] Kasatkin, A. G. 1971. The main processes and apparatuses of chemical technology (in Russian). Khimiya, Moscow, 784 pp.

[40] Levy, Y. and Kushnir Y. (1981) Laboratory measurements of nucleation processes and the growth of gypsum in the Mediterranean - Dead Sea mixed brine. Geological Survey of Israel Report and Weizmann Inst. Sci. 18.

[41] Lerman, A. 1979. Geochemical processes: water and sediment environments. John Wiley \& Sons. 262-266, 420-434.

[42] CRC Handbook of Chemistry and Physics. 1979-1980. $60^{\text {th }}$ edition. R. C. Weast (ed.). CRC Press, Boca Raton, Florida, p. B-67. 